\title{
Role of Hope and Resilience in the Outcome of Depression and Related Suicidality
}

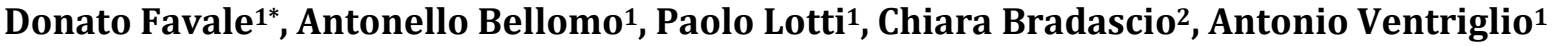 \\ ${ }^{1}$ Department of Clinical and Experimental Medicine, University of Foggia, Foggia, Italy \\ ${ }^{2}$ School of Education and Psychology, University of Bolton, Bolton, United Kingdom \\ Email: ${ }^{\star d o f a v a l e @ g m a i l . c o m ~}$
}

How to cite this paper: Favale, D., Bellomo, A., Lotti, P., Bradascio, C., \& Ventriglio, A. (2020). Role of Hope and Resilience in the Outcome of Depression and Related Suicidality. Psychology, 11, 428-435. https://doi.org/10.4236/psych.2020.113028

Received: January 20, 2020

Accepted: March 14, 2020

Published: March 17, 2020

Copyright (c) 2020 by author(s) and Scientific Research Publishing Inc. This work is licensed under the Creative Commons Attribution International License (CC BY 4.0).

http://creativecommons.org/licenses/by/4.0/ (c) (i) Open Access

\begin{abstract}
Depression is a common disease that reduces the quality of life and limits seriously patient's psychosocial functioning. The aim of this study is to investigate the role of hope and resilience in depressive disease outcomes and suicidality. Seven rating scales (Brief Psychiatric Rating Scale, Hamilton Rating Scale for Depression, Montgomery-Asberg Depression Rating Scale, Hospital Anxiety and Depression Scale, the Enhanced Snyder Hope Scale, Scale of Connor and Davidson-10, Scale for Suicide Ideation) have been administered to 75 subjects with the following features: diagnosis of unipolar depressive disorder, bipolar disorder and schizoaffective disorder reporting a major current depressive episode according to DSM-V criteria, age between 18 and 75 years, no history of drug addiction, major medical condition or mental retardation. An inverse correlation has been found between higher levels of hope and resilience and lower severity of depression $(p<0.0001)$ among the sample and higher levels of resilience were associated with lower levels of suicidality $(p=0.037)$. Furthermore, an inverse correlation between age and levels of resilience ( $p=$ $0.020)$, an association between age and years of disease $(p<0.0001)$ as well as between resilience and levels of hope $(p<0.0001)$ were found. Hope and resilience both seem to have a positive role in the outcome of depressive illness reducing the severity of psychopathology and related suicidality.
\end{abstract}

\section{Keywords}

Hope, Resilience, Depression, Suicide

\section{Introduction}

Depression is a common disease that reduces the quality of life and limits seriously patients' psychosocial functioning. The outcome of depressive illness is charac- 
terized by an acute phase ( 6 - 12 weeks) mostly associated to an intense and active treatment. Remission of symptomatology occurs after psychopharmacological and/or psychotherapeutic trials and a maintenance phase is sustained in order to prevent any relapse. Recovery is considered as the absence of sub-syndromic symptoms for more than 6 months (Frank et al., 1991).

Suicide is an important social and medical problem and during the second and third decades of life suicide represents the second leading cause of death after car accidents. Suicides related to depression mostly occur in elder age and many subjects may also report psychotic symptoms (Ganguli \& Mulsant, 2002; Vythilingam et al., 2003). Suicide attempts and suicides in bipolar disorder are often related to the first depressive episode around 25 years (Simpson \& Jamison, 1999). Several studies conducted in the last 10 - 15 years described a relationship between levels of resilience and suicidal risk. In fact, resilience seems to be a protective factor against suicidal risk. According to the Interpersonal Theory of Suicide (ITPS; 32) factors promoting suicide are: Thwarted belongingness (feeling of social isolation), Perceived burdensomeness (feeling to be a burden for others) and Acquired capability for suicide (habit not to fear the death and pain originating from a preventive exposure to painful events). Also, IPTS hypothesizes that the absence of hope may lead to the desire for death. According to Snyder's theory (Snyder et al., 2000), hope is defined as the degree in which people have a sense of determination to achieve success (agency though) and perceive the capability to form alternative paths towards the realization of objectives (pathways though). In addition, Davidson et al. hypothesized that higher levels of hope determined lower levels of all three IPTS components (Davidson et al., 2009). They also suggested that suicidality in subjects with elevated levels of hope may also occur since they may have many aims to reach and report an experience of failure that contributes to capability for suicide.

Hope can be considered a starting point for the recovery process and it is the basis of determination which is very important to achieve any goal (Adams \& Hope, 1998). Patients' motivation can be increased by a higher sense of hope to engage in the recovery process (Park, 2016). The key elements of hope are represented by courage, faith, projects, expectation and the future.

Resilience is a term that refers to the ability, the process or the result of a satisfactory adaptation, despite the threatening or difficult circumstances that an individual faces in his/her life (Malaguti, 2005; Trabucchi, 2007). Then resilience is the capacity to transform a potentially destabilizing and critical event into a personal search which allows an individual to reorganize positively his life (La Marca et al., 2014). Resilience is not considered an "innate force" but is a dynamic process which develops throughout the entire life as a personality aspect, reinforces psychological well-being despite the existence of a mental illness (Putton \& Fortugno, 2006). Hope and resilience may play an important role in the outcome of depressive disease and in suicidality. As mentioned above, Snyder has proposed a theory of hope (Snyder et al., 2000) that can be defined as a state of positive motivation based on three components: Aims to reach: Goal blockage, 
Strategies to reach objectives/Pathways Thinking, Motivation to reach objectives/Agency Thinking.

DSM-V (Diagnostic and Statistical Manual of Mental Disorders) in 2013 listed nine symptoms as diagnostic criteria for depression. Snyder (Snyder et al., 1994) has previously discussed that nine diagnostic symptoms of depression are related to the three components of hope. Goal blockage relates especially with worthlessness feelings and suicidal thoughts/attempts; Agency with diminished interest and loss of energy/fatigue; Pathways in particular relates to inability to concentrate.

In this study we described the relationship between levels of hope and resilience with the gravity of depressive psychopathology, suicidality and other clinical or demographic variables among a sample of patients affected by mood disorders reporting a current depressive episode.

\section{Materials and Methods of the Study}

The sample used in the study is composed by patients enrolled at Mental Health Community Centre of Foggia and University of Foggia Psychiatric Unit between December 2018 and August 2019.

Patients included in the study met the following criteria:

a) Diagnosis of unipolar depressive disorder, bipolar disorder and schizoaffective disorder reporting a current depressive episode according to criteria of (American Psychiatric Association, 2013);

b) Age between 18 and 75 years;

c) Absence of history of substance addiction lifetime;

d) Absence of a psychiatric disease due to another medical condition;

e) Absence of mental retardation.

Finally, we enrolled 55 patients with depressive unipolar disease, 18 patients with bipolar disorder with current depressive episode, 2 patients with schizoaffective disorder with current depressive episode.

Seven rating scales have been administered: BPRS (Brief Psychiatric Rating Scale) for measuring general psychopathology, HAMD (Hamilton Rating Scale for Depression) and MADRS (Montgomery-Asberg Depression Rating Scale) to evaluate depressive symptoms, HADS (Hospital Anxiety and Depression Scale) commonly used to measure levels of depression and anxiety, SNYDER (The Enhanced Snyder Hope Scale) to evaluate levels of hope, CD-RISC 10 (Scale of Connor and Davidson) to analyse levels of resilience, SSI (Scale for Suicide Ideation) to evaluate suicidal ideation.

Descriptive analyses (percentages of frequency, mean and standard deviations) were performed, ANOVA and linear regressions have been carried out for bivariate analyses. Significative results have been considered with $p \leq 0.05$.

\section{Results}

The sample is composed of 28 males and 47 females. The average age is 48 years. The majority of patients is single, followed by married and divorced, most of pa- 
tients are employed (Table 1).

Considering scores obtained from psychometric scales, mean values for the gravity of the psychopathology through BPRS are $42.52 \pm 12.95$, considered as a moderate gravity of psychopathology. Gravity of depression has been described with two psychometric scales obtaining mean values for HAMD of $20 \pm 7.45$ and for MADRS of $23.45 \pm 11.22$, considered as moderate gravity of depression.

The evaluation of anxiety in comorbidity with depression through HADS has determined scores with mean values of $18.84 \pm 9.06$, considered as clinically relevant anxiety.

Positive psychosocial characteristics of hope and resilience have been measured respectively with Snyder and CD-RISC 10 with mean values for the first of $41.17 \pm 11.20$ and for the second of $17.78 \pm 7.66$. The mean score for the Snyder is considered as "hopeful" for the sample and CD-RISC 10 score is considered as "less resilient" sample in comparison with the mean value $(22.3 \pm 7.6)$ reported in literature for depressive disorders.

Table 1. Clinical and sociodemographic descriptive characteristics of the sample.

\begin{tabular}{|c|c|c|}
\hline Characteristics & mean \pm s.d. & $\mathrm{N}(\%)$ \\
\hline Male sex & - & $28(37.34)$ \\
\hline Female sex & - & $47(62.66)$ \\
\hline Age & $47.77 \pm 14.68$ & - \\
\hline \multicolumn{3}{|l|}{ Marital status } \\
\hline Single & - & $41(54.66)$ \\
\hline Married & - & $29(38.66)$ \\
\hline Separate & - & $5(6.66)$ \\
\hline \multicolumn{3}{|l|}{ Employment } \\
\hline Employed & - & $33(44)$ \\
\hline Unemployed & - & $25(33.33)$ \\
\hline Retired & - & $7(9.33)$ \\
\hline Student & - & $10(13.33)$ \\
\hline \multicolumn{3}{|l|}{ Hospitalizations } \\
\hline 0 & - & $38(50.66)$ \\
\hline 1 & - & $3(4)$ \\
\hline$>1$ & - & $34(45.33)$ \\
\hline Years of disease & $13.66 \pm 13.27$ & - \\
\hline \multicolumn{3}{|l|}{ Diagnosis } \\
\hline Major Depression & - & $55(73.33 \%)$ \\
\hline Bipolar Disorder, depressive episode & - & $18(24 \%)$ \\
\hline Schizoaffective Disorder, depressive episode & - & $2(2.66 \%)$ \\
\hline
\end{tabular}


Suicidality has been measured through SSI obtaining mean scores of $6.65 \pm$ 6.33 (Table 2).

Through a bivariate analysis for sex, we observed differences between females and males within the sample at psychometric scales, years of disease, number of hospitalizations and age.

In fact, significative differences have been observed in the scores of BPRS with mean values for females of $36.57 \pm 13.30$ and $47.20 \pm 12.77$ for males ( $p$-value $0.195)$.

The gravity of depression (HAMD) is higher in females with mean values of $21.57 \pm 7.56$ than in males with $13 \pm 3.24(p$-value $=0.040)$.

Also, women have a statistically longer outcome of disease (years) with 18.57 \pm 15.14 than males with $1.6 \pm 1.14$ s.d. ( $p$-value $=0.033$ ). Furthermore, women report higher levels of depression $(p$-value $=0.040)($ Table 3$)$.

Table 2. Psychometric descriptive features of the sample.

\begin{tabular}{cc}
\hline Psychometric ratings & mean \pm s.d. \\
\hline BPRS & $42.52 \pm 12.95$ \\
HAMD & $20 \pm 7.45$ \\
MADRS & $23.45 \pm 11.22$ \\
HADS & $18.84 \pm 9.06$ \\
Snyder & $41.17 \pm 11.20$ \\
CD-RISC 10 & $17.78 \pm 7.66$ \\
SSI & $6.65 \pm 6.33$ \\
\hline
\end{tabular}

Table 3. Gender differences of the sample in the scores of psychometric scales, for years of disease and for number of hospitalizations.

\begin{tabular}{cccc}
\hline Characteristics & $\begin{array}{c}\text { Females } \\
\text { mean } \pm \text { s.d. }\end{array}$ & $\begin{array}{c}\text { Males } \\
\text { mean } \pm \text { s.d. }\end{array}$ & $p$-value \\
BPRS & $36.57 \pm 13.30$ & $47.20 \pm 12.77$ & 0.195 \\
HAMD & $21.57 \pm 7.56$ & $13 \pm 3.24$ & 0.040 \\
MADRS & $25.57 \pm 11.68$ & $13.60 \pm 6.18$ & 0.065 \\
HADS & $15.85 \pm 3.76$ & $18 \pm 6.44$ & 0.481 \\
Snyder & $37.42 \pm 8.88$ & $40.88 \pm 9.31$ & 0.539 \\
CD-RISC 10 & $18.57 \pm 6.21$ & $20.20 \pm 5.49$ & 0.649 \\
SSI & $13.14 \pm 4.25$ & $14 \pm 2.82$ & 0.704 \\
Years of disease & $18.57 \pm 15.14$ & $1.6 \pm 1.14$ & 0.033 \\
Number of hospitalizations & 47 & 28 & 0.067 \\
Age & $48.14 \pm 16.49$ & $34.40 \pm 21.66$ & 0.238
\end{tabular}


Depressive patients report much higher gravity of depression at HAMD ( $p$-value $=0.002)$ and MADRS ( $p$-value $=0.005)$ than bipolar/schizoaffective disorders patients. Also, patients affected by schizoaffective disorders report more years of illness ( $p$-value $=0.052$; Table 4 ). A significant association is described between higher levels of hope at Snyder as well as resilience at CD-RISC 10 and lower severity of depression at HAMD and MADRS $(p<0.0001)$ as well as between higher levels of resilience and lower levels of suicidality at SSI $(p=0.037)$. Furthermore, an inverse association between age and resilience $(p=0.020)$ as well as an association between age and years of disease $(p<0.0001)$ are reported (Table 5$)$.

Table 4. Psychopathology ratings among diagnosis groups.

\begin{tabular}{ccccc}
\hline $\begin{array}{c}\text { Psychometric } \\
\text { ratings }\end{array}$ & Major Depression & Bipolar Disorder & $\begin{array}{c}\text { Schizoaffective } \\
\text { disorder }\end{array}$ & $p$-value \\
\hline BPRS & $42.30 \pm 11.57$ & $44.78 \pm 16.54$ & $28 \pm 4.24$ & 0.217 \\
HAMD & $21.69 \pm 7.16$ & $15.72 \pm 5.92$ & $12 \pm 11.31$ & $\mathbf{0 . 0 0 2}$ \\
MADRS & $25.90 \pm 10.63$ & $17.11 \pm 10.11$ & $13 \pm 14.14$ & 0.005 \\
HADS & $20.09 \pm 7.46$ & $15.66 \pm 12.02$ & $13 \pm 16.97$ & 0.129 \\
Snyder & $39.61 \pm 11.14$ & $45.83 \pm 8.02$ & $42 \pm 31.11$ & 0.123 \\
CD-RISC 10 & $17.25 \pm 7.27$ & $18.94 \pm 8.89$ & $22 \pm 8.48$ & 0.533 \\
SSI & $7.16 \pm 6.20$ & $4.44 \pm 5.39$ & $12.5 \pm 14.84$ & 0.118 \\
Age & $46.63 \pm 15.42$ & $50.83 \pm 11.08$ & $51.50 \pm 27.57$ & 0.544 \\
Years of disease & $11.69 \pm 12.31$ & $18 \pm 14.54$ & $29 \pm 15.55$ & $\mathbf{0 . 0 5 2}$ \\
\hline
\end{tabular}

Table 5. Tested associations between psychopathology and hope-resilience ratings.

\begin{tabular}{ccccccccc}
\hline Characteristics & BPRS & HAMD & MADRS & HADS & Snyder & $\begin{array}{c}\text { CD- } \\
\text { RISC 10 }\end{array}$ & SSI & Age \\
\hline Snyder & 0.022 & $<0.0001$ & $<0.0001$ & $<0.0001$ & - & $<0.0001$ & 0.237 & 0.136 \\
CD-RISC 10 & 0.676 & $<0.0001$ & $<0.0001$ & $<0.0001$ & $<0.0001$ & - & 0.037 & $\mathbf{0} 0.020$ \\
Years of disease & 0,078 & 0.776 & 0.692 & 0.665 & 0.381 & 0.729 & 0.678 & $<0.0001$ \\
\hline
\end{tabular}

\section{Discussion}

In this study we describe the role of hope and resilience in the outcome of depression and in suicidality.

Arnau et al. conducted a longitudinal study examining the influence of hope on depression in 522 students of a college (Arnau et al., 2007) in three different moments (with intervals of one month) and showed that agency thinking exercised a negative predictive effect on depression, while levels of pathways thinking didn't influence levels of depression (Arnau et al., 2007). In another study resilience has been investigated as a protective factor for anxiety and depressive mood among Korean employees (Young-Chul \& Sang, 2019). 
We observe lower values of hope and resilience in patients with diagnosis of major depression than in patients with diagnosis of bipolar disorder in depressive phase, even if not fully statistically significant. This difference may be explained according to a Spanish study by Fierro and Molina, 2015 (Fierro, 2016): emotional dimming is the main element in bipolar depression while sadness in unipolar depression. A more passive and painful experience justifies lower levels of hope in unipolar depression. There are significatively higher values of depressive symptoms (HAMD and MADRS) in unipolar depressed patients than in bipolar ones. We show that the length of disease is higher in patients affected by schizoaffective disorder with depression followed by bipolar and finally unipolar depression. The major length of schizoaffective disorder is linked to the features of this syndrome that stands across bipolar disease and schizophrenia. It has a typical outcome of bipolar disease, but it also presents psychotic symptoms without depression or mania. This study concludes that the outcome of disease in patients affected by depressive episode depends on objective factors such as socio-demographic characteristics (age, gender, occupation) and on subjective factors such as psychosocial characteristics of resilience and hope.

\section{Conclusion}

Results from our study suggest to include rehabilitation interventions and psychotherapy in the treatment of different phases of the depressive illness in order to improve healing factors such as hope and resilience and guarantee greater therapeutic effectiveness through synergic action with conventional treatments for a more favourable outcome of depression.

\section{Conflicts of Interest}

The authors declare no conflicts of interest regarding the publication of this paper.

\section{References}

Adams, S. M. P., \& Hope, D. J. (1998). The Critical Factor in Recovery. Journal of Psychosocial Nursing \& Mental Health Services, 36, 29-32.

American Psychiatric Association (2013). Diagnostic and Statistical Manual of Mental Disorders, Fifth Edition, DSM V. Washington, D.C.: American Psychiatric Publishing. https://doi.org/10.1176/appi.books.9780890425596

Arnau, R. C., Finch, J. F., Rhudy, J. L., \& Fortunato, V. J. (2007). Longitudinal Effects of Hope on Depression and Anxiety: A Latent Variable Analysis. Journal of Personality, 75, 43-64. https://doi.org/10.1111/j.1467-6494.2006.00432.x

Davidson, C. L., Wingate, L. R., Rasmussen, K. A., \& Slish, M. L. (2009). Hope as a Predictor of Interpersonal Suicide Risk. Suicide and Life-Threatening Behavior, 39, 499-507. https://doi.org/10.1521/suli.2009.39.5.499

Fierro, M. (2016). Differences in Subjective Experience between Unipolar and Bipolar Depression. Revista Colombiana de Psiquiatria, 45, 162-169.

https://doi.org/10.1016/j.rcp.2015.09.006 
Frank, E., Prien, R. F., Jarrett, R. B., Keller, M. B., Kupfer, D. J., \& Lavori, P. W. (1991). Conceptualization and Rationale for Consensus Definitions of Terms in Major Depressive Disorder: Remission, Recovery, Relapse, and Recurrence. Archives of General Psychiatry, 48, 851-855. https://doi.org/10.1001/archpsyc.1991.01810330075011

Ganguli, H. H., Dodge, H. H., \& Mulsant, B. H. (2002). Rates and Predictors of Mortality in an Aging, Rural, Community-Based Cohort: The Role of Depression. Archives General Psychiatry, 59, 1046-1052. https://doi.org/10.1001/archpsyc.59.11.1046

La Marca, A., Festeggiante, M., \& Schiavone, S. (2014). Docenti precari: Resilienza e promozione ddel benessere. Giornale Italiano della Ricerca Educativa, 7, 129-144.

Malaguti, E. (2005). Educarsi alla resilienza. Come affrontare crisi e difficoltà e migliorarsi: Centro Studi Erickson.

Park, J. C. R. K. (2016). Positive Psychology and Hope as Means to Recovery from Mental Illness. Journal of Applied Rehabilitation Counseling, 47, 34-42. https://doi.org/10.1891/0047-2220.47.2.34

Putton, A., \& Fortugno, M. (2006). Affrontare la vita. Che cos'è la resilienza e come svilupparla. Roma: Carocci.

Simpson, S. G., \& Jamison, K. R. (1999). The Risk of Suicide in Patients with Bipolar Disorders. The Journal of Clinical Psychiatry, 60, 53-56.

Snyder, C. R., Ilardi, S. S., Cheavens, J., Michael, S. T., Yamhure, L., \& Sympson, S. (2000). The Role of Hope in Cognitive Behavior Therapies. Cognitive Therapy and Research, 24, 747-762.

Snyder, C. R., La Pointe, A., Crowson, J. J., \& Early, S. (1994). Preferences of High and Low Hope People for Self-Referential Input. Cognition and Emotion, 12, 807-823. https://doi.org/10.1080/026999398379448

Trabucchi, P. (2007). Resisto dunque sono. Chi sono i campioni della resistenza psicologica e come fanno a convivere felicemente con lo stress. Milano: Corbaccio.

Vythilingam, M. C., Bremner, J. D., Mazure, C. M., Maciejewsky, P. K., \& Nelson, J. C. (2003). Psychotic Depression and Mortality. American Journal of Psychiatry, 160, 574-576. https://doi.org/10.1176/appi.ajp.160.3.574

Young-Chul Shin, S. M. K., \& Sang, W. J. (2019). Resilience as a Protective Factor for Depressive Mood and Anxiety among Korean Employees. Journal of Korean Medical Science, 34, e188. https://doi.org/10.3346/jkms.2019.34.e188 